\title{
SHIPS SHORE SERVICE OPTIMIZATION USING THE QUEUEING THEORY
}

\author{
Bebic, D. ; Stazic, L. ${ }^{* *} \&$ Komar, I.** \\ ${ }^{*}$ Gearbulk Norway AS, N-5160 Laksevag, Bergen, Norway \\ ${ }^{* *}$ University of Split, Faculty of Maritime Studies, R. Boskovica 37, Split, Croatia \\ E-Mail:dragan.bebic@gearbulk.com, lstazic@pfst.hr,ikomar@pfst.hr
}

\begin{abstract}
This paper is presenting a solution for simplifying shore maintenance service teams scheduling procedure in the maritime industry. Shore maintenance service teams scheduling procedure in the past required either advanced mathematical knowledge in the area of the queueing theory or adequate computerized software for the calculation. That action in the past was usually outsourced; companies did not have personnel capable of solving the queueing theory nor the software needed for the calculation. The solution, presented in the paper, enables in-house scheduling of the shore maintenance service teams using only basic knowledge of the theory, without the use of the specially designed software. The scheduling is performed using a simplified Excel template for Queueing theory, inserting the data from ship's Computerized Planned Maintenance System. The Excel template, after filling the data, determines the optimal number of teams for the fleet and performs the calculation according to the desired or optimal service level. Simplified Excel template for Queueing theory cut the costs for the calculation and scheduling enabling additional savings in the industry.

(Received in June 2019, accepted in October 2019. This paper was with the authors 3 weeks for 1 revision.)
\end{abstract}

Key Words: Queueing Process, Arrival Rate, Service Time, Service Team, System Utilization, Maintenance, Costs

\section{INTRODUCTION}

Maritime shipping business is highly dependable on numerous global factors (Fig. 1) and therefore subjected to constant changes in the business model and adjustments according to the industry benchmarking of the OPEX (Vessel daily OPerating EXpenses). The competition on today's shipping market is vast [1], like in all other industries ("the manufacturing industry is currently under strong pressure to swiftly and easily adapt to changes" [2]), especially when considering that supply and demand are not in balance for an extended period of time. Therefore, shipping companies are facing a constant challenge to run a profitable business. In that respect the most common way to remain profitable and win the contract before the competition is cutting the OPEX. However, most of the budget accounts in the OPEX are already at the minimum, and further cutting would endanger the safety of the vessels. During the time, some of the maritime companies observed that budget for the crew costs represent great part of the OPEX expenses [3], and considerable savings can be achieved by hiring less expensive crew (according to research performed by authors, yearly savings can accumulate up to $\$ 130.000$ per vessel, which is significant part of the Bulk Carrier OPEX). Most of the shipping companies are following this path. The side effect of the less expensive crew is visible in the poorer maintenance and increase of damage cases and unplanned maintenance, mostly rectified on high cost by shore services. This happens because less expensive crew is, in general, less skilled too. In most companies, this consequence was calculated, and as long as the damage cases price tag is lower than savings on the crew expenses, the risk is acceptable. To prevent malfunctions which can be created by less skilled crew, companies are turning towards shore-based service for the maintenance of the vital equipment. The idea of shore service maintenance for the vital equipment and the machinery 
is not new. Certain companies are using this kind of support, modified according their preferences.

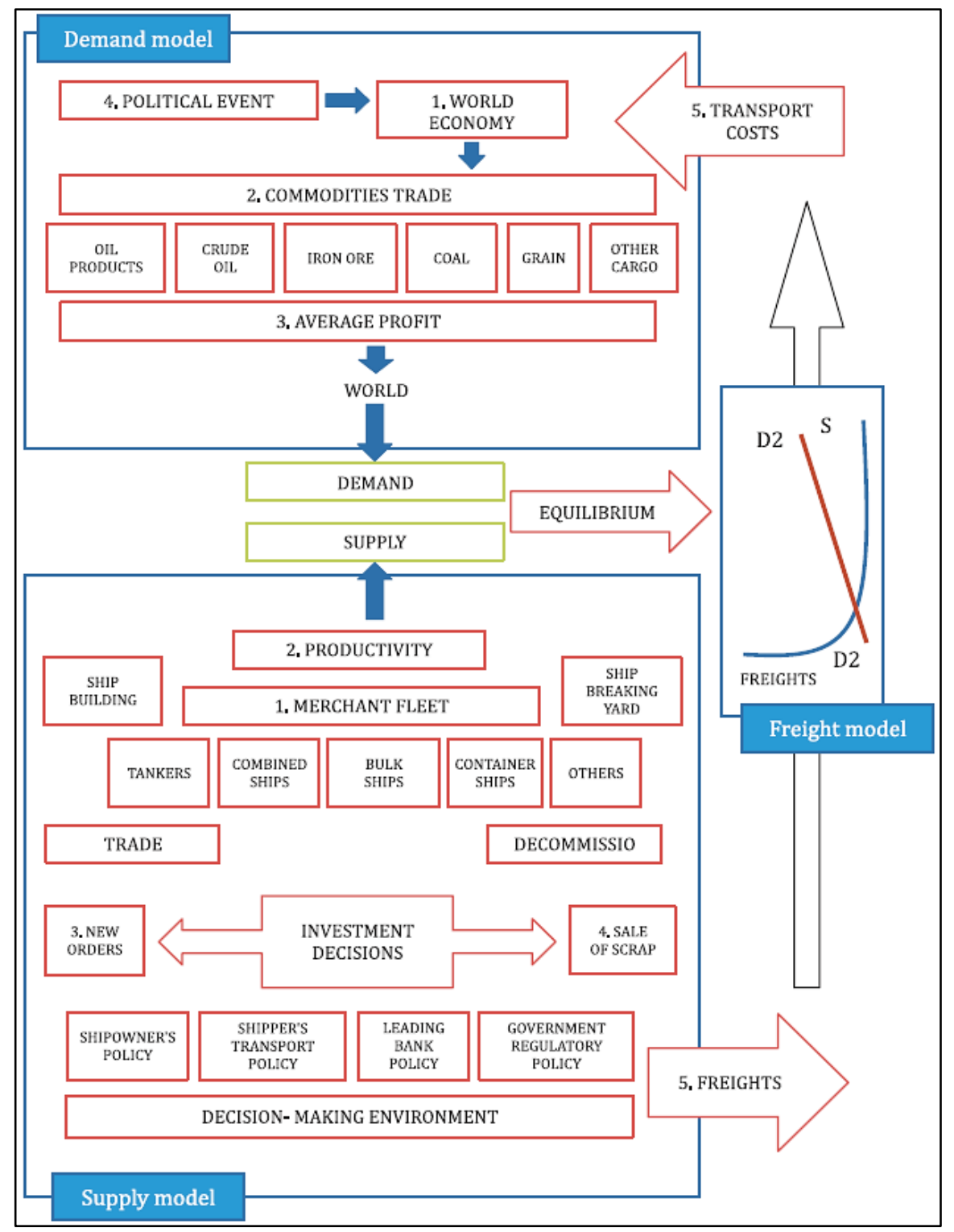

Figure 1: The shipping market model $[4,5]$.

Example of a modification is servicing of diesel aggregates which could be either entirely overhauled by shore service or they can have ready on the stock reconditioned spare parts for on-board delivery when the engine is due for an overhaul. The crew needs to replace these components on the engine and send back replaced parts for reconditioning. Shore service maintenance tends to increase in intensity in the future, not just because on-board crews are becoming less skilled, but as consequence of the development of autonomous ships. The cost for this kind of service arrangement is in the range of $\$ 15,000-\$ 35,000$ per engine, depending of the type and size of the engine.

To decrease the costs of the service arrangement, shipping companies are creating inhouse service teams, often created with specialized intentions. These teams should consist of experienced engineers and mechanics familiar with this kind of job (preferably excrewmembers of the same company). Proper scheduling of such teams is "an important function that determines the efficiency and productivity" [6] and requires quite advanced knowledge of the queuing theory or some computerized program as an aid. Usually, that 
knowledge is not available in the conservative shipping industry environment [7] and companies have to hire consultants to perform the action or to buy software designed for the action. Both actions require additional costs which will diminish potential savings of the whole arrangement.

Queuing and scheduling problems are known for a long time [8], especially in the land transport sector, with a several solutions proposed for the problem [9-11]. In the manufacturing and industry sector, optimization, queuing and scheduling is also addressed by multitude of different solutions for problems $[12,13]$. Most of the mentioned solutions are applicable in the maritime and shipping industry, but actual usage is limited due to price and attitude of the human factor.

This paper analyses usage of the simplified Excel template for Queueing theory as a problem-solving solution for organizing schedule for in-house service teams for diesel generator overhaul, an example created only for comparison purposes. Use of this template should solve the problem of the scheduling of the shore maintenance service teams using only basic knowledge of the theory, without the use of the specially designed software, therefore cutting the expenses needed for the software or the consultancy.

Real fleet of 45 vessels has been analysed in this example, together with the actual data, all in order to facilitate a proper base for realistic calculation. Queueing theory $[14,15]$ is used for this type of the calculation.

\section{QUEUEING THEORY APPROACH FOR CASE ANALYSIS}

The queuing theory is one of the methods of operational research that studies the problems of queuing, whose content is the serving of randomly received units or requests for a service [16]. In the analysed case, due to a specific approach, the classic structure of the queueing system (customer arrival - waiting for service - servers - leaving the system) is changed. The change is visible in the fact that all the elements still exist, but the service teams are coming to the vessel (customer), not the other way around.

Queueing theory is quite complicated [17], requires advanced mathematical knowledge and therefore has not been used widely for practical problem solving. Team at the Alberta University created a highly useful Queueing "tool pack 4.0" application for Excel [18] as a tool for solving queuing and scheduling problems. The app is easy to use, although it is still required the basic knowledge of Queueing theory for setting up the problem.

The base for the calculation is the data of all generator engines on 45 vessels. The data is collected usually from ship's computerized PMS - Planned Maintenance System (such as Amos, Bassnet, Sertica or similar) where all necessary data (TBO - time between overhaul; average daily running hours, date of overhauls) is available. This data enables calculation of next due overhaul dates, if not calculated by PMS.

Table I: Diesel generator data for fleet of 45 vessels.

\begin{tabular}{|c|c|c|c|c|c|c|}
\hline Item no. & $\begin{array}{l}\text { Vessel code - } \\
\text { Eng. no }\end{array}$ & $\begin{array}{c}T B O \text { as per } \\
\text { instr. Manual }\end{array}$ & $\begin{array}{c}\text { Average daily } \\
\boldsymbol{R} \boldsymbol{H}\end{array}$ & $\begin{array}{c}\text { First } \\
\text { overhaul }\end{array}$ & $\begin{array}{c}\text { Second } \\
\text { overhaul }\end{array}$ & $\begin{array}{c}\text { Third } \\
\text { overhaul }\end{array}$ \\
\hline 1 & Vsl_A_Eng_1 & 20,000 & 12.20 & $24 / 09 / 2008$ & $21 / 03 / 2013$ & $15 / 09 / 2017$ \\
\hline 2 & Vsl_A_Eng_2 & 20,000 & 11.30 & $29 / 03 / 2009$ & $31 / 01 / 2014$ & $06 / 12 / 2018$ \\
\hline 3 & Vsl_A_Eng_3 & 20,000 & 11.50 & $01 / 10 / 2007$ & $05 / 07 / 2012$ & $09 / 04 / 2017$ \\
\hline 132 & $\mid \overline{V s l} \cdot \overline{A S}$ Engng_1 & $\cdot \overline{16,000}$ & $\overline{11.43}$ & $\overline{05 / 09 / 2009}$ & $\overline{05} \cdot \overline{07} \cdot \overline{2013}$ & $\overline{05 / 05 / 2017}$ \\
\hline 133 & Vsl_AS_Eng_2 & 16,000 & 8.42 & $09 / 01 / 2011$ & $23 / 03 / 2016$ & $05 / 06 / 2021$ \\
\hline 134 & Vsl_AS_Eng_3 & 16,000 & 10.12 & $01 / 03 / 2010$ & $29 / 06 / 2014$ & $27 / 10 / 2018$ \\
\hline
\end{tabular}


Table II: Time between vessels arrival into Queueing system.

\begin{tabular}{|c|c|c|}
\hline Vessel code - Eng. no. & Date of planned overhaul & Time between vessel's arrival (days) \\
\hline Vsl_C_Eng_1 & $02 / 10 / 2006$ & 1 \\
\hline Vsl_W_Eng_1 & $13 / 10 / 2006$ & 11 \\
\hline Vsl_I_Eng_2 & $07 / 11 / 2006$ & 25 \\
\hline $\begin{aligned} & \boldsymbol{E}: \text { 二:ニ:ニ:ニ:ニ:二: } \\
& \text { Vsl_AL_Eng_1 }\end{aligned}$ & ニ:ニ:ニ:ニ:ニ:ニ:ニ:ニ:ニ: & :ニ:ニ:ニ:ニ:ニ:ニ:ニ:ニ:ニ:ニ: \\
\hline Vsl_A_Eng_2 & $06 / 12 / 2018$ & 27 \\
\hline Vsl_AR_Eng_3 & $31 / 12 / 2018$ & 25 \\
\hline \multicolumn{2}{|c|}{ Total number of units in interval (2006-2018) } & 378 \\
\hline \multicolumn{2}{|c|}{ Total number of days in interval (2006-2018) } & 4474 \\
\hline \multicolumn{2}{|r|}{ Average number of units per day } & 0.08449 \\
\hline
\end{tabular}

Data in Table II is sorted in ascending order and shows an overview of time between vessels arrival (due date for engine overhaul). Table III represents the summary of the characteristics of the queueing process, used in the final calculation.

Table III: Queueing process summary from the Table II.

\begin{tabular}{|c|c|c|}
\hline \multicolumn{3}{|c|}{ Characteristics of Queueing Process } \\
\hline Average time interval between two units (days) & $t_{\text {arr }}$ & 11.83858 \\
\hline Arrival rate (per day) & $\lambda$ & 0.8449 \\
\hline Service rate (per day) & $\mu$ & 0.10345 \\
\hline
\end{tabular}

Arrival rate $\lambda$ was calculated from the data in the Table II using Eq. (1):

$$
\lambda=\frac{\text { Total number of units in interval }(2006-2018)}{\text { Total number of days in interval }(2006-2018)}
$$

Service rate $\mu$ was calculated by Eq. (2):

$$
\mu=(\text { Average value of options } 1,2 \& 3)^{-1}
$$

where:

- Engine overhaul completed during one port stay. Total of six days.

- The vessel's port stay is less than six days, so the service team stays onboard for crossing short distance to the next port. Service team spent nine days onboard.

- The vessel's port stay is less than six days, so the service team stays onboard for crossing long distance to the next port. Service team spent 14 days onboard.

It is already given that use of the particular queueing model depends on the specific system to be analysed. Queueing models [19] are identified with combination of letters

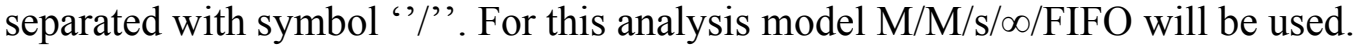

The meaning of $\mathrm{M} / \mathrm{M} / \mathrm{s} / \infty / \mathrm{FIFO}$ model is:

- M - stands for Markovian process. By this process, arrival or service rate follows a Poisson distribution, while the exponential distribution describes the time between arrivals or service time.

- $\mathrm{s}-$ stands for the number of servers.

- $\infty$ - refers to infinite system capacity.

- FIFO - refers to queue discipline (First in - first out). 


\section{CONFIRMATION OF A MARKOVIAN PROCESS}

To confirm the first condition of a Markovian process (time between arrivals follows exponential distribution), Table IV derives from data for all fleet.

Table IV: Annual mean time between vessels arrival.

\begin{tabular}{|c|c|c|}
\hline Year & Mean time (days) & $\lambda$ \\
\hline 2007 & 11 & 0.09239 \\
\hline 2008 & 9 & 0.11732 \\
\hline 2009 & 8 & 0.11953 \\
\hline 2010 & 11 & 0.08849 \\
\hline 2011 & 10 & 0.10099 \\
\hline 2012 & 11 & 0.08761 \\
\hline 2013 & 11 & 0.08824 \\
\hline 2014 & 11 & 0.09284 \\
\hline 2015 & 11 & 0.08742 \\
\hline 2016 & 18 & 0.05567 \\
\hline 2017 & 21 & 0.04861 \\
\hline 2018 & 27 & 0.03762 \\
\hline Average & $\mathbf{1 3}$ & $\mathbf{0 . 0 8 4 7 3}$ \\
\hline
\end{tabular}

Data in the Table V is calculated by exponential distribution - Eq. (3) [20]:

$$
f(x)=\lambda e^{-\lambda x}
$$

Table V: Density in time interval for randomly chosen functions from Table IV.

\begin{tabular}{|c|c|c|c|}
\hline Interval & Density function $\lambda=0.11953$ & Density function $\lambda=\mathbf{0 . 0 5 5 6 7}$ & Density function $\lambda=0.08473$ \\
\hline 0 & 0.1195 & 0.0557 & 0.0847 \\
\hline 1 & 0.1061 & 0.0527 & 0.0778 \\
\hline 2 & 0.0941 & 0.0498 & 0.0715 \\
\hline-62 & $-\cdot-\cdot-\cdot \overline{0} \cdot-\overline{0}$ & $-\cdot-\cdot-\overline{0.0018}$ & $\cdot-\cdot-\overline{0.0004}$ \\
\hline 63 & 0.0001 & 0.0017 & 0.0004 \\
\hline 64 & 0.0001 & 0.0016 & 0.0004 \\
\hline
\end{tabular}

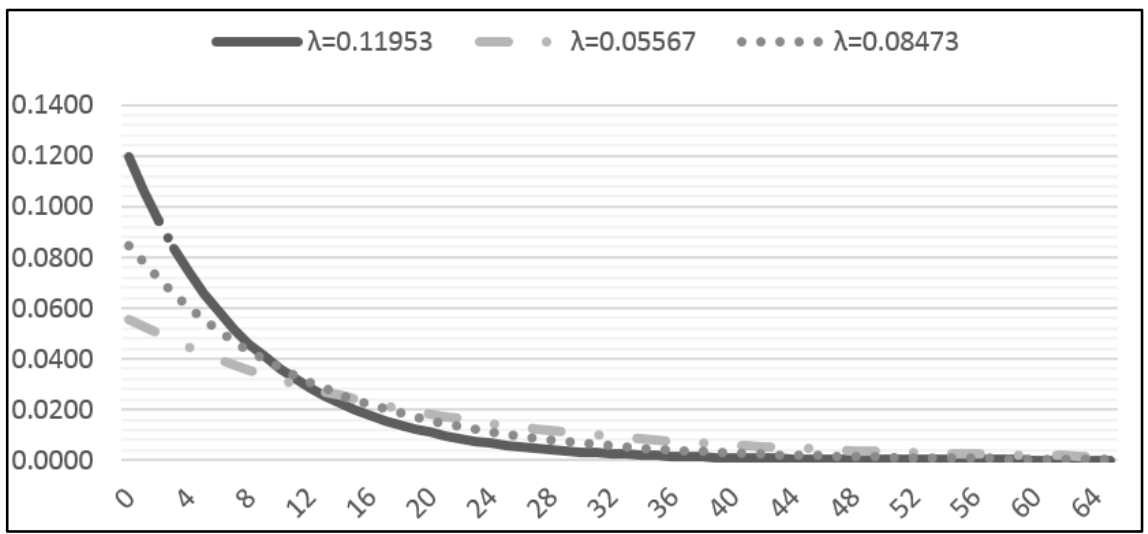

Figure 2: Time between vessels arrival (exponential distribution). 
Distribution of vessels arrival rate (the second condition of a Markovian process) is calculated by Eq. (4) [21]:

$$
P(k)=\frac{\lambda^{k} \cdot e^{-\lambda}}{k !}
$$

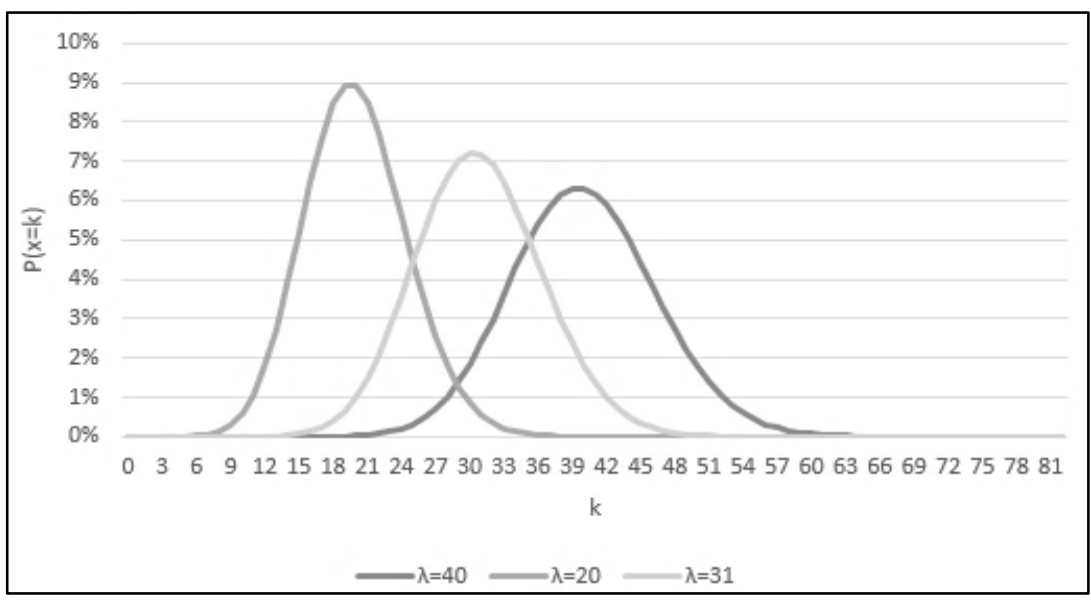

Figure 3: Vessels arrival rate (Poisson distribution).

According to the results shown in Figs. 2 and 3, a Markovian process is confirmed for the analysed case.

\section{CALCULATION}

The template [18] will perform the final calculation after entering the following data:

- Arrival rate 0.08449 , received from Table III,

- Service rate 0.10345 , received from Table III,

- Desired service level,

- Threshold time (It is period of time, given in days, needed to complete the service. This time can be inserted from user's experience, maker's maintenance handbook or some data handbook [22].),

- Number of service personnel (service teams).

Desired service level (90\%) and threshold time (15 days) are set considering predesigned use of diesel aggregates on board cargo vessels. The majority of the cargo vessels have three units, two of them are more than enough to fulfil all requirements of the ship, either at sea or in port under cargo operation. The third unit is redundancy and therefore operability of the vessel itself is not in question if expected time in queue increases a couple of days. Besides, observing from the point of the ship-owner, increase the desired service level over the specific limit, might request additional service team, and consequently, additional cost.

Number of service personnel (service teams) is a variable which should be changed during the calculation. Usually, the calculation starts with one service team (cheapest solution), value should be increased until desired service level and threshold time are obtained.

Fig. 4 presents the results of one of the basic performance measures (and quick preview) of the system efficiency, for one service team. That is the probability of the number of ships in the service process per number of units in a queue. For example, if ten vessels are in the system at the same time (which is the case in analysed company), probability that vessel will not be in a queue is only $2.4 \%$, telling that the system with one service team is not efficient at all. 


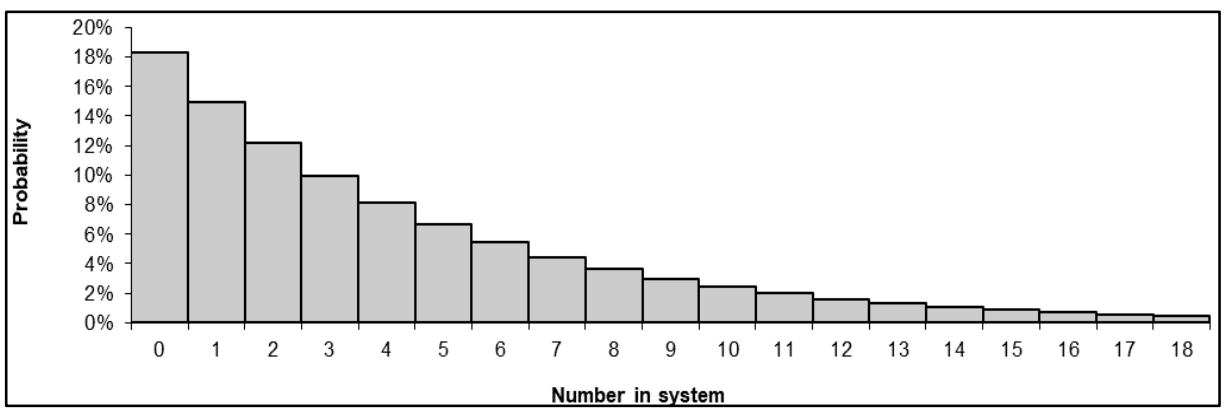

Figure 4: Probability for number of vessels in system, based on calculation for one service team.

The Template shown in Fig. 5 presents data calculated for one service team.

\begin{tabular}{|c|c|c|c|c|c|}
\hline \multicolumn{6}{|c|}{ M/M/s Queueing Calculations } \\
\hline \multicolumn{6}{|c|}{ Basic Param eters } \\
\hline$\lambda$ & Arrival Rate & 0.08449 per day & Number in system & Number in queue & Probability \\
\hline$\mu$ & Service Rate & 0.10345 per day & & $\begin{array}{ll}0 & 0\end{array}$ & $18 \%$ \\
\hline $\mathrm{S}$ & Number of Teams & 1 & & 0 & $15 \%$ \\
\hline \multirow[t]{2}{*}{$\mathrm{t}$} & Time Unit & day & & 1 & $12 \%$ \\
\hline & & & & 2 & $10 \%$ \\
\hline \multicolumn{3}{|c|}{ Basic Perform ance Measures } & & 3 & $8 \%$ \\
\hline \multirow{7}{*}{$\begin{array}{l}\rho_{S} \\
P(0) \\
L q \\
L q \\
L q \\
W q \\
W \\
P(n)\end{array}$} & Utilization & $82 \%$ & & 4 & $7 \%$ \\
\hline & Probability that the system is empty & $18 \%$ & & 5 & $5 \%$ \\
\hline & Expected number in queue & 3.6395 & & 6 & $4 \%$ \\
\hline & $L$, expected number in system & 4.4562 & & 7 & $4 \%$ \\
\hline & Expected time in queue & 43.0761 & & 8 & $3 \%$ \\
\hline & Expected total time in system & 52.7426 & 1 & 9 & $2 \%$ \\
\hline & Probability that customer waits & $82 \%$ & 1 & 10 & $2 \%$ \\
\hline$(n)$ & & & 1 & 11 & $2 \%$ \\
\hline \multicolumn{2}{|r|}{ Advanced Parameters } & & 1 & 12 & $1 \%$ \\
\hline \multirow{3}{*}{\multicolumn{2}{|c|}{$\begin{array}{l}\text { Threshold time } \\
\text { Desired service level }\end{array}$}} & 15 days & 1 & 13 & $1 \%$ \\
\hline & & $90 \%$ & 1 & 14 & $1 \%$ \\
\hline & & & 1 & 15 & $1 \%$ \\
\hline \multicolumn{3}{|c|}{ Advanced Performance Measures } & 1 & 16 & $1 \%$ \\
\hline & Current service level & $39 \%$ & 1 & 17 & $0 \%$ \\
\hline & Number of Teams required to & & & & \\
\hline & achieve desired service level & 2 & 1 & 18 & $0 \%$ \\
\hline & & & 2 & 19 & $0 \%$ \\
\hline & & & Total & & $\mathbf{9 9} \%$ \\
\hline
\end{tabular}

Figure 5: Queueing calculation for one service team [18].

It is visible that obtained results for one service team are not optimal. The current service level for one team is only $39 \%$, far from the desired service level of $90 \%$. It means that only $39 \%$ of the vessels will be serviced in the desired threshold time of 15 days. The remaining $61 \%$ of the ships will have to wait for the service. Besides, 'Basic Performance Measures' is showing that the expected total time in the system is too long, almost 53 days. As calculation for one service team is not satisfactory, calculation for two service teams should be performed.

Fig. 6 presents the calculation results for two teams.

Similar to the probability graph in Fig. 4, the graph in Fig. 7 presents the probability of the total number of vessels in the system for two service teams. A quick comparison of these two graphs illustrates the point of the advantage of the system with two service teams. For example, only four vessels are expected with the probability of $2.4 \%$ in the graph in Fig. 7 , while expectancy in Fig. 4 is ten ships for the same likelihood. Comparison of Figs. 4 and 7 shows that less number of the ships presented in the graph for the corresponding expectation is in direct relation to the efficiency of the system. 


\begin{tabular}{|c|c|c|c|c|c|}
\hline \multicolumn{6}{|c|}{ M/M/s Queueing Calculations } \\
\hline \multicolumn{6}{|c|}{ Basic Param eters } \\
\hline$\lambda$ & Arrival Rate & 0.08449 per day & Number in system & Number in queue & Probability \\
\hline$\mu$ & Service Rate & 0.10345 per day & 0 & 0 & $42 \%$ \\
\hline $\mathrm{S}$ & Number of Teams & 2 & 1 & 0 & $34 \%$ \\
\hline \multirow[t]{2}{*}{$\mathrm{t}$} & Time Unit & day & 2 & 0 & $14 \%$ \\
\hline & & & 3 & 1 & $6 \%$ \\
\hline \multicolumn{3}{|c|}{ Basic Performance Measures } & 4 & 2 & $2 \%$ \\
\hline$\rho_{s}$ & Utilization & $41 \%$ & 5 & 3 & $1 \%$ \\
\hline$P(0)$ & Probability that the system is empty & $42 \%$ & 6 & 4 & $0 \%$ \\
\hline $\mathrm{Lq}$ & Expected number in queue & 0.1635 & 7 & 5 & $0 \%$ \\
\hline Lq & $\mathrm{L}$, expected number in system & 0.9802 & 8 & 6 & $0 \%$ \\
\hline Wq & Expected time in queue & 1.9346 & s & 7 & $0 \%$ \\
\hline W & Expected total time in system & 11.6011 & 10 & 8 & $0 \%$ \\
\hline \multirow[t]{2}{*}{$\mathrm{P}(\mathrm{n})$} & Probability that customer waits & $24 \%$ & 11 & 9 & $0 \%$ \\
\hline & & & 12 & 10 & $0 \%$ \\
\hline \multicolumn{3}{|c|}{ Advanced Parameters } & 13 & 11 & $0 \%$ \\
\hline & Threshold time & 15 days & 1 & 12 & $0 \%$ \\
\hline \multirow{2}{*}{\multicolumn{2}{|c|}{ Desired service level }} & $90 \%$ & 15 & 13 & $0 \%$ \\
\hline & & & 16 & 14 & $0 \%$ \\
\hline \multicolumn{3}{|c|}{ Advanced Performance Measures } & 17 & 15 & $0 \%$ \\
\hline & & $96 \%$ & 18 & 16 & $0 \%$ \\
\hline & Number of Teams required to & & & & \\
\hline & achieve desired service level & 2 & 15 & 17 & $0 \%$ \\
\hline & & & 20 & 18 & $0 \%$ \\
\hline & & & Total & & $100 \%$ \\
\hline
\end{tabular}

Figure 6: Queueing calculation for two service teams [18].

The output results significantly differ from the previous calculation. The current service level increases to $96 \%$, above the desired service level. The expected total time in the system drops from 53 days to 12 days and the expected time in the queue drops from 43 to 2 days.

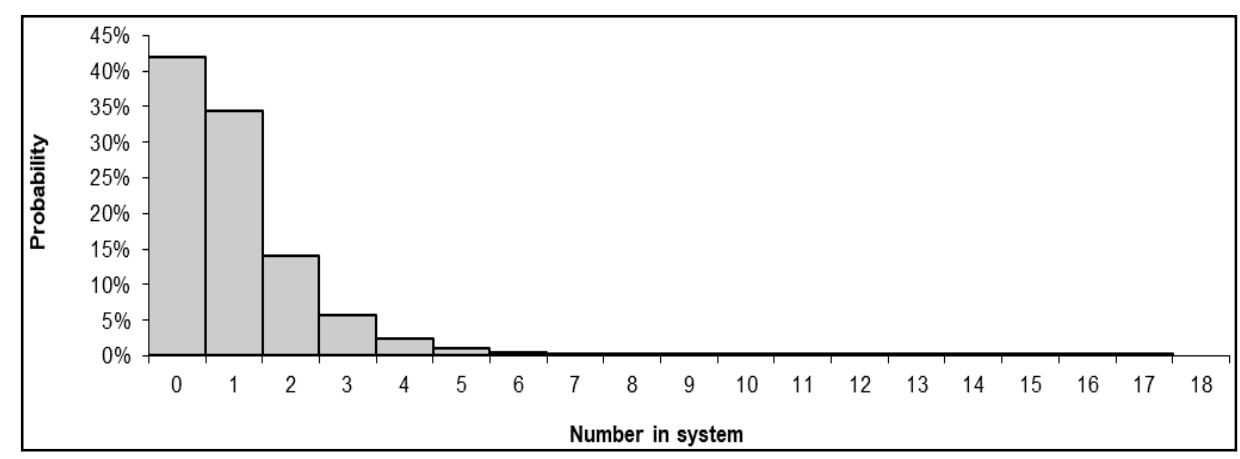

Figure 7: Probability for number of vessels in the system, based on calculation for two service teams.

Results obtained for two service teams fulfil all required conditions and the calculation should finish there, any further calculation does not have any economical or logical reason; that is confirmed with the calculation shown in Fig. 8.

Service utilization for three service teams dropped to only $27 \%$. Also, based on the template calculation, two service teams are optimum to achieve the desired service level (see at the bottom of Fig. 8).

According to the analysis, conclusion is that two service teams are sufficient to fulfil requirements for servicing 45 vessels within a threshold time of 15 days and at the desired service level of $90 \%$.

Increase of the desired service level to higher value of $95 \%$ will yield exactly same results shown in Fig. 6, with current service level of $96 \%$. Further increase of the desired service level will lead to the situation presented in Fig. 8, to an extreme drop in system utilization as well as a considerable cost for the additional service team. 


\begin{tabular}{|c|c|c|c|c|c|}
\hline \multicolumn{6}{|c|}{ M/M/s Queueing Calculations } \\
\hline \multicolumn{6}{|c|}{ Basic Parameters } \\
\hline$\lambda$ & Arrival Rate & 0.08449 per day & Number in system & Number in queue & Probability \\
\hline$\mu$ & Service Rate & 0.10345 per day & & $\begin{array}{ll}0 & 0\end{array}$ & $44 \%$ \\
\hline S & Number of Servers & 3 & & 0 & $36 \%$ \\
\hline \multirow[t]{2}{*}{$\mathrm{t}$} & Time Unit & day & & 0 & $15 \%$ \\
\hline & & & & 0 & $4 \%$ \\
\hline \multicolumn{3}{|c|}{ Basic Performance Measures } & & 1 & $1 \%$ \\
\hline$\rho_{S}$ & Utilization & $27 \%$ & & 2 & $0 \%$ \\
\hline$P(0)$ & Probability that the system is empty & $44 \%$ & & 3 & $0 \%$ \\
\hline Lq & Expected number in queue & 0.0205 & & 4 & $0 \%$ \\
\hline $\mathrm{Lq}$ & $\mathrm{L}$, expected number in system & 0.8372 & & 5 & $0 \%$ \\
\hline Wq & Expected time in queue & 0.2428 & & 6 & $0 \%$ \\
\hline W & Expected total time in system & 9.9093 & 1 & 7 & $0 \%$ \\
\hline \multirow[t]{2}{*}{$\mathrm{P}(\mathrm{n})$} & Probability that customer waits & $5 \%$ & 1 & 8 & $0 \%$ \\
\hline & & & 1 & 9 & $0 \%$ \\
\hline \multicolumn{3}{|c|}{ Advanced Parameters } & 1 & 10 & $0 \%$ \\
\hline & Threshold time & 15 days & 1. & 11 & $0 \%$ \\
\hline \multirow{2}{*}{\multicolumn{2}{|c|}{ Desired service level }} & $90 \%$ & 1 & 12 & $0 \%$ \\
\hline & & & 1 & 13 & $0 \%$ \\
\hline \multicolumn{3}{|c|}{ Advanced Performance Measures } & 1 & 14 & $0 \%$ \\
\hline & & $100 \%$ & 1 & 15 & $0 \%$ \\
\hline & Number of servers required to & & & & \\
\hline & achieve desired service level & 2 & 1 & 16 & $0 \%$ \\
\hline & & & 2 & 17 & $0 \%$ \\
\hline & & & Total & & $100 \%$ \\
\hline
\end{tabular}

Figure 8: Queueing calculation for three service teams [18].

\section{PRACTICAL VALUE}

This simplified Excel template for Queueing theory can be used in practice in every shipping company where can save a significant amount of money and time. Costs of the calculation of the queuing and scheduling vary from the arrangement, in general between $\$ 8,000$ and $\$ 20,000$, for every calculation.

The annual cost for service teams [23] is:

- Annual cost for two experienced engineers: $\$ 8,000 \times 12 \times 2=\$ 192,000$,

- Annual cost for two experienced mechanics: $\$ 2,500 \times 12 \times 2=\$ 60,000$,

- Total annual cost for two in-house service teams: $\$ 192,000+\$ 60,000=\$ 252,000$.

The number of annual arrivals for service ( $\lambda$ in Table VI) affect service teams cost through the amount of traveling, as they are on the fixed yearly payment system. Based on annual average arrivals, the calculation for flight cost is:

- Annual cost for team travels: $64 \times \$ 500=\$ 32,000$.

Based on the above calculation, the total annual cost for in-house teams, including annual travels, would be $\$ 284,000$. If this sum is divided to 45 vessels, it will increase vessel budget for $\$ 6,311$ per year.

The cost for shore service team is in the range of $\$ 15,000$ to $\$ 35,000$ for an intervention, based on whether specialized maker service team or independent small service companies are performing the job. The majority of the ship-owners for the job would prefer small service companies (which are cheaper for similar quality of service), providing they have a license for a particular engine. Therefore, the cost calculation for shore service team (Table VI) is based on a lower value of $\$ 15,000$ per one service. 
Table VI: Annual cost comparison.

\begin{tabular}{|c|c|c|c|}
\hline Year & $\lambda$ & In-house service team cost (incl. Travel cost) & Shore service team cost (incl. Travel cost) \\
\hline 2007 & 34 & $\$ 286,000$ & $\$ 544,000$ \\
\hline 2008 & 43 & $\$ 295,000$ & $\$ 688,000$ \\
\hline 2009 & 40 & $\$ 292,000$ & $\$ 640,000$ \\
\hline 2010 & 35 & $\$ 287,000$ & $\$ 560,000$ \\
\hline 2011 & 36 & $\$ 288,000$ & $\$ 576,000$ \\
\hline 2012 & 32 & $\$ 284,000$ & $\$ 512,000$ \\
\hline 2013 & 32 & $\$ 284,000$ & $\$ 512,000$ \\
\hline 2014 & 35 & $\$ 287,000$ & $\$ 560,000$ \\
\hline 2015 & 30 & $\$ 282,000$ & $\$ 480,000$ \\
\hline 2016 & 20 & $\$ 272,000$ & $\$ 320,000$ \\
\hline 2017 & 19 & $\$ 271,000$ & $\$ 304,000$ \\
\hline 2018 & 14 & $\$ 266,000$ & $\$ 224,000$ \\
\hline \multicolumn{2}{|c|}{ Total cost: } & $\$ 3,394,000$ & $\$ 5,920,000$ \\
\hline \multicolumn{2}{|c|}{ Savings: } & $\$ 2,526,000$ & \\
\hline
\end{tabular}

Fig. 9 presents comparison of data from Table VII. It is evident that maintaining in-house service teams is much economically sound option than hiring shore teams when service is required. The only exception is for the year 2018 when shore service cost is cheaper than inhouse service team. However, this is due to extremely low arrival rate $\lambda=14$ (half of the average arrival date).

Use of the simplified Excel template for Queueing theory, as shown in the paper, can save additionally $3.2 \%$ (up to $7.9 \%$ ) of total savings which will be spent on the calculation of the queuing and scheduling.

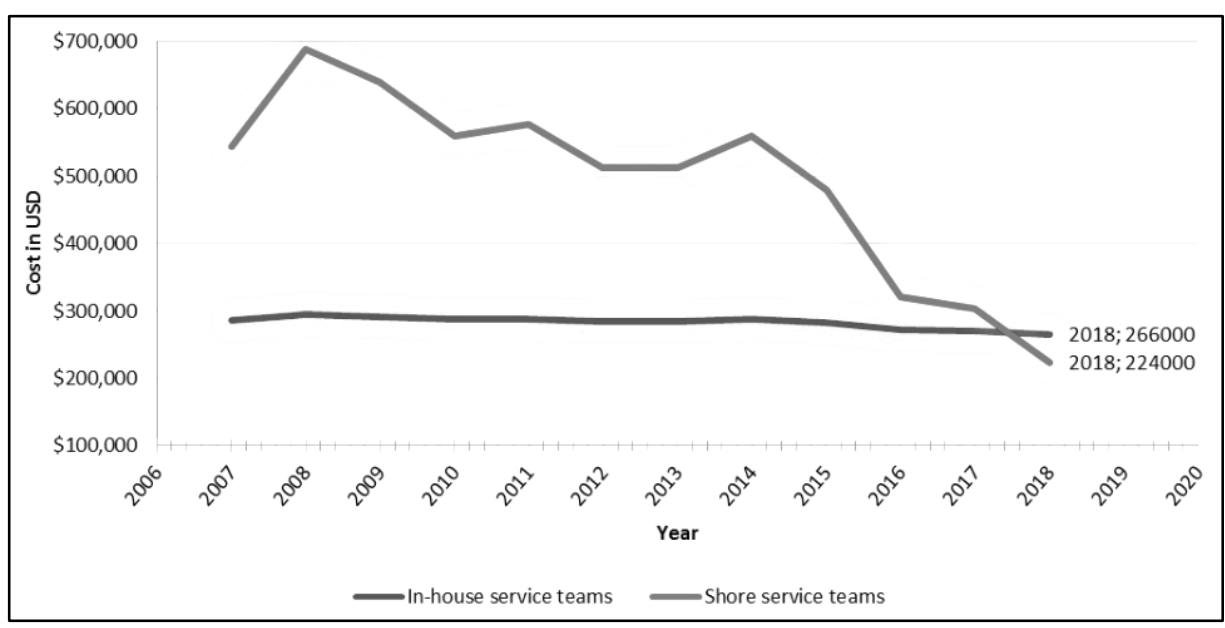

Figure 9: Cost comparison.

\section{CONCLUSION}

The demanding maritime market requires frequent reductions in operating costs. The creation of in-house service teams, which would perform overhauls of some important machinery, imposes itself as a necessity which will enable some savings. Creation of those teams raises the question of how to determine the optimal number of teams for each particular fleet and how to optimally organize the team's scheduling by ships in the fleet. In order to answer these 
two questions, advanced knowledge of the Queueing theory is needed, often not present among the employees in shipping companies.

Application of the simplified Excel template for Queueing theory, as shown in the paper, removed the need of advanced knowledge of the Queueing theory for the task. Calculation of the optimal number of in-house service teams is turned into something simple, into entering the data from company Planned Maintenance System into the template. This method has determined the optimal number of in-house service teams (two teams) for the analysed fleet, obtaining a service level of $96 \%$.

Potential creation of the in-house service teams and following scheduling performed with the simplified Excel template for Queueing theory for analysed example shows possible savings of more than $\$ 2,526,000$ for the fleet.

In the highly competitive shipping market, the correct decision makes the differences as well as an advantage on the market. Presented model is intended to be clear, simple and easy to understand; an example how to cheaply solve the queuing and scheduling problem in the maritime industry. It will not yield the kind of savings which might significantly influence the company's business, but it is indeed the example of how use of the simple tool and proper analysis might deliver data for the correct decision. Besides, the efficiency of any company depends on the right decision made on each level, no matter how small saving it might result.

\section{REFERENCES}

[1] Kemene, A. (2018). Shipping Market Overview, Optima Shipping Services, China Ship and Finance Summit, from https://www.marinemoney.com/system/files/media/201805/1\%20Angelica\%20Kemene.pdf, accessed on 02-01-2019

[2] Vrecko, I.; Kovac, J.; Rupnik, B.; Gajsek, B. (2019). Using queuing simulation model in production process innovations, International Journal of Simulation Modelling, Vol. 18, No. 1, 47-58, doi:10.2507/IJSIMM18(1)458

[3] Chubb, N. (2018). Three ways to reduce your OpEx without compromising on performance, Intelligent Cargo Systems, from https://www.intelligentcargosystems.com/three-ways-to-reduceyour-opex-without-compromising-on-performance, accessed on 20-03-2019

[4] Stopford, M. (2009). Maritime Economics, $3^{\text {rd }}$ edition, Supply, demand and freight rates (p. 116), Routledge / Taylor \& Francis, London

[5] Jugović, A.; Komadina, N; Perić Hadžić, A. (2015). Factors influencing the formation of freight rates on maritime shipping markets, Pomorstvo - Scientific Journal of Maritime Research, Vol. 29, No. 1, 23-29

[6] Aydemir, E.; Koruca, H. I. (2015). A new production scheduling module using priority-rule based genetic algorithm, International Journal of Simulation Modelling, Vol. 14, No. 3, 450-462, doi:10.2507/IJSIMM14(3)7.299

[7] Manuel, M. E. (2012). Maritime Risk and Organizational Learning, Ashgate Publishing Ltd., Surrey

[8] Ceder, A. (1984). Bus frequency determination using passenger count data, Transportation Research Part A: General, Vol. 18, No. 5-6, 439-453, doi:10.1016/0191-2607(84)90019-0

[9] Hartmann Tolić, I.; Martinović, G.; Crnjac Milić, D. (2018). Optimization methods in modern transportation systems, Technical Gazette, Vol. 25, No. 2, 627-634, doi:10.17559/TV20170326212717

[10] Niu, H.; Zhou, X.; Gao, R. (2015). Train scheduling for minimizing passenger waiting time with time-dependent demand and skip-stop patterns: Nonlinear integer programming models with linear constraints, Transportation Research Part B: Methodological, Vol. 76, 117-135, doi:10.1016/j.trb.2015.03.004

[11] Gkiotsalitis, K.; Alesiani, F. (2019). Robust timetable optimization for bus lines subject to resource and regulatory constraints, Transportation Research Part E: Logistics and Transportation Review, Vol. 128, 30-51, doi:10.1016/j.tre.2019.05.016 
[12] Gingu (Boteanu), E. I.; Zapciu, M.; Cavalieri, S. (2017). Production systems flow modelling using decomposition method and required buffers, International Journal of Simulation Modelling, Vol. 16, No. 2, 207-218, doi:10.2507/IJSIMM16(2)2.367

[13] Gao, S.; Rubrico, J. I. U.; Higashi, T.; Kobayashi, T.; Taneda, K.; Ota, J. (2019). Efficient throughput analysis of production lines based on modular queues, IEEE Access, Vol. 7, 9531495326, doi:10.1109/ACCESS.2019.2928309

[14] Sztrik, J. (2012). Basic Queueing Theory, University of Debrecen, Faculty of Informatics, Debrecen

[15] Zenzerović, Z. (2003). Queueing Theory (Teorija redova čekanja), Maritime Faculty in Rijeka, Rijeka (in Croatian)

[16] Krpan, L.; Maršanić, R.; Milković, M. (2017). A model of the dimensioning of the number of service places at parking lot entrances by using the queuing theory, Technical Gazette, Vol. 24, No. 1, 231-238, doi:10.17559/TV-20160128161848

[17] Campello, F.; Ingolfsson, A.; Shumsky, R. A. (2017). Queueing models of case managers, Management Science, Vol. 63, No. 3, 587-900, doi:10.1287/mnsc.2015.2368

[18] Ingolfsson, A.; Gallop, F. (2013-14). Queueing ToolPak 4.0, Template for Waiting Line Analysis, from http://queueingtoolpak.org/qtp40/distribution40/template.xls, accessed on 25-092017

[19] Bhat, U. N. (2015). An Introduction to Queueing Theory: Modeling and Analysis in Applications, $2^{\text {nd }}$ edition, Birkhäuser, Basel

[20] McCool, J. I. (2012). Using the Weibull Distribution: Reliability, Modeling and Inference, John Wiley \& Sons, Inc., Hoboken

[21] Moore, D. S.; McCabe, G. P; Craig, B. A. (2017). Introduction to the Practice of Statistics, $9^{\text {th }}$ edition, W. H. Freeman \& Co., New York

[22] SINTEF Technology and Society, NTNU (2015). OREDA: Offshore and Onshore Reliability Data Handbook, $6^{\text {th }}$ edition, Oreda Participants, Det Norske Veritas, Germanischer Lloyd

[23] PayScale, - Salary Comparison, Salary Survey, Search Wages, from https://www.payscale.com/, accessed on 22-02-2019 